\title{
Modeling Anomalous Surface - Wave Propagation Across the Southern Caspian Basin
}

\author{
K. F. Priestley \\ H. J. Patton \\ C. A. Schultz
}

January 9,1998

This is an informal report intended primarily for internal or limited external distribution. The opinions and conclusions stated are those of the author and may or may not be those of the Laboratory.

Work performed under the auspices of the U.S. Department of Energy by the Lawrence Livermore National Laboratory under Contract W-7405-Eng-48. 


\section{DISCLAIMER}

This document was prepared as an account of work sponsored by an agency of the United States Government. Neither the United States Government nor the University of California nor any of their employees, makes any warranty, express or implied, or assumes any legal liability or responsibility for the accuracy, completeness, or usefulness of any information, apparatus, product, or process disclosed, or represents that its use would not infringe privately owned rights. Reference herein to any specific commercial product, process, or service by trade name, trademark, manufacturer, or otherwise, does not necessarily constitute or imply its endorsement, recommendation, or favoring by the United States Government or the University of California. The views and opinions of authors expressed herein do not necessarily state or reflect those of the United States Government or the University of California, and shall not be used for advertising or product endorsement purposes.

This report has been reproduced directly from the best available copy.

Available to DOE and DOE contractors from the Office of Scientific and Technical Information

P.O. Box 62, Oak Ridge, TN 37831

Prices available from (615) 576-8401, FTS 626-8401

Available to the public from the

National Technical Information Service

U.S. Department of Commerce

5285 Port Royal Rd.,

Springfield, VA 22161 


\title{
Modeling Anomalous Surface-Wave Propagation Across the Southern Caspian Basin
}

\author{
Keith F. Priestley, Howard J. Patton, and Craig A. Schultz
}

\begin{abstract}
The crust of the south Caspian basin consists of $15-25 \mathrm{~km}$ of low velocity, highly attenuating sediment overlying high velocity crystalline crust. The Moho depth beneath the basin is about $30 \mathrm{~km}$ as compared to about $50 \mathrm{~km}$ in the surrounding region. Preliminary modeling of the phase velocily curves shows that the thick sediments in the south Caspian basin are also under-lain by a $30-35 \mathrm{~km}$ thick crystalline crust and not by typical oceanic crust. This analysis also suggests that if the effect of the over-pressuring of the sediments is to reduce Poissons' ratio, the over-pressured sediments observed to $\sim 5 \mathrm{~km}$ do not persist to great depths. It has been known since the 1960's that the south Caspian basin blocks the regional phase Lg. Intermediate frequency $(0.02-0.04 \mathrm{~Hz})$ fundamental-mode Rayleigh waves propagating across the basin are also severely attenuated, but the low frequency surface waves are largely unaffected. This attenuation is observed along both east-to-west and west-to-east great circle paths across the basin, and therefore it cannot be related to a seismograph site effect. We have modcled the responsc of surface waves in an idcalized rendition of the south Caspian basin model using a hybrid normal-mode/2-D finite difference approach. To gain insight into the features of the basin which cause the anomalous surface wave propagation, we have varied parameters of the basin model and computed synthetic record sections to compare with the observed seismograms. We varied the amount of mantle up-warp, the shape of the boundaries, the thickness and shear wave $Q$ of the sediments and mantle, and the depth of the water layer. Of these parameters, the intermediate frequency surface waves are most.severely affected by the sediment thickness and shear wave attenuation. Fundamental mode Rayleigh wave phase velocities measured for paths crossing the basin are cxtremcly low.
\end{abstract}




\section{Introduction}

The crust and upper mantle structure of the south Caspian Basin is enigmatic. Early Soviet studies (Gal'perin et al, 1962; Neprochnov et al, 1968; Rezanov and Chamo, 1969; Neprochnov et al, 1970; Yegorkin and Matushkin, 1970) show that the crust of the basin consists of two layers: a thick sedimentary section $(15-25 \mathrm{~km})$ with low $\mathrm{P}$-wave velocity $(3.5-$ $4.0 \mathrm{~km} / \mathrm{s}$ ) overlying a $12-18 \mathrm{~km}$ thick basaltic lower crust. Mangino and Priestley (1998) analyzed receiver functions from teleseismic events recorded on four broadband seismographs of the Caspian Seismic Network (CSN) located on the periphery of the basin (Fig. 1) to determine the crustal structure beneath these sites and compared these models with the crustal structure beneath the IRIS seismograph station at ABKT. This study showed that the crust in Turkmenia along the trend of the Apshceron-Balkhan Sill - Kopet Dag Mountains (Fig. 1 - KRF, NBD, and ABKT) is $50 \mathrm{~km}$ thick. In the southwestern part of the Caspian basin (LNK - Fig. 1) the $33 \mathrm{~km}$ thick crust consists of a $13 \mathrm{~km}$ thick sedimentary section lying on a high velocity $\left(V_{p} \sim 7.1 \mathrm{~km} \mathrm{~s}^{-1}\right)$ lower crustal section. In the southeastern part of the basin (KAT - Fig. 1) the crust is $30 \mathrm{~km}$ thick and consists of a $10 \mathrm{~km}$ thick sedimentary section overlying a $20 \mathrm{~km}$ thick low velocity $\left(\mathrm{V}_{\mathrm{p}} \sim 5.8 \mathrm{~km} \mathrm{~s}^{-1}\right)$ crystalline crust. Mangino and Priestley (1998) combined the receiver function models with simplified velocity models from the previous Russian Deep Seismic Sounding (DSS) results to form a $1800 \mathrm{~km}$ long ESEWNW trending crustal cross-section across the Kura Depression, the south Caspian basin and the Kopet Dag Mountains (Fig. 1). The most significant features of this crustal model are the $20 \mathrm{~km}$ variation in thickness of Cenozoic sedimentary basin deposits, the absence of a "granitic" $\left(\mathrm{V}_{\mathrm{p}} \sim 5.8-6.5 \mathrm{~km} \mathrm{~s}^{-1}\right)$ crustal layer in the central part of the south Caspian basin, and $20 \mathrm{~km}$ of crustal thinning beneath the central part of the basin. The Moho beneath the south Caspian basin has a broad arch-like structure whose western boundary is a relatively narrow zone across which the crust thins rapidly ( $\sim 20 \mathrm{~km}$ thinning over a $100 \mathrm{~km}$ zone) and whose eastern boundary has a more gradual change in crustal thickness $(\sim 20 \mathrm{~km}$ thinning over a $400 \mathrm{~km}$ zone).

Early Soviet studies showed that the regional seismic phase $\mathrm{L}_{\mathrm{g}}$ was blocked for propagation paths across the south Caspian basin (Savarensky and Valdner, 1960; Mindeli et 
al 1965). $\mathrm{L}_{\mathrm{g}}$ is sensitive to changes in crustal structure along its propagation path and is absent in seismograms after propagating across $\sim 150 \mathrm{~km}$ of oceanic crust (Press \& Ewing, 1952). Other studies have shown the conversion of oceanic $S_{n}$ to continental $L_{g}$ (Shurbet, 1964, 1975; Isacks \& Stephens, 1975; Seber et al, 1993) or the conversion of continental $\mathrm{L}_{\mathrm{g}}$ to oceanic $\mathrm{S}_{\mathrm{n}}$ (Shapiro et al, 1996) at the continent-ocean boundary. Kadinsky-Cade et al. (1981) demonstrate that $\mathrm{L}_{\mathrm{g}}$ is blocked for paths crossing the south Caspian Basin while propagating efficiently in the surrounding region. On the other hand, $\mathrm{S}_{\mathrm{n}}$ propagates efficiently for paths across the south Caspian but inefficiently in the region south and west of the basin. This is clearly demonstrated by the seismograms in Figure 2 for an earthquake near KRF (Fig. 1) on the castern shorcline of the central Caspian Sca. The crust in the vicinity of the epicenter is abont $50 \mathrm{~km}$ thick (Mangino and Priestley, 1998). The Preliminary Determination of Epicenter depth for the event is $40 \mathrm{~km}$ but because focal depths in this area are not well constrained, it is not clear whether the event is in the crust or mantle. Jackson and Priestley (unpublished work) have used waveform modeling to constrain the depth at $45 \mathrm{~km}$, placing it in the crust. The seismogram at LNK on the southwestern coastline shows an impulsive $S_{n}$ phase but little energy in the $L_{g}$ group velocity window. The crust between KRF and ABKT has nearly a uniform thickness of $50 \mathrm{~km}$. The seismogram at ABKT shows an $\mathrm{S}_{\mathrm{n}}$ and $\mathrm{L}_{\mathrm{g}}$ phase typical of that seen on stable continental paths. The seismogram at KAT near the southeastern coastline is anomalous, with a clear $\mathrm{S}_{\mathrm{I}}$ phase which is followed by a high amplitude long duration coda.

In this report we examine surface wave propagation across the south Caspian basin. We show that the fundamental mode Rayleigh wave phase velocities are extremely low and that intermediate frequency fundamental mode surface waves propagating across the south Caspian Basin are severely attenuated. We examine the effect of the south Caspian basin structure on the propagation of surface waves by computing finite difference synthetic surface wave seismograms for an idealized rendition of the south Caspian basin crustal model shown in Figure 1. We then vary the crustal and upper mantle parameters of the idealized model and recompute the synthetic seismograms to examine which of these parameters most influence the surface wave propagation across the basin. 


\section{Surface wave observations}

We have determined inter-station phase velocity dispersion curves from teleseismic surface wave trains for the paths KRF-LNK, LNK-KAT, and KAT-KRF (Fig. 1). The phase velocity measurements were made using the constrained least-squares method of Gomberg et al (1988) in which the phase velocity measurement is considered as a linear filter estimation problem. If $S_{1}(\omega)$ is the Fourier transform of the Rayleigh wave seismogram at station 1 , then $S_{2}(\omega)$, the transformed seismogram at station 2 after propagating the distance, $\Delta \mathrm{r}$, along a great circle path between the stations, is given by

$$
S_{2}(\omega)=F(\omega) S_{1}(\omega)
$$

where $\omega$ is the angular frequency. The Earth filter $F(\omega)$ may be written

$$
F(\omega)=e^{-\gamma(\omega) \Delta r} e^{i k(\omega) \Delta r}=A(\omega) e^{i \phi(\omega)}
$$

where $k(\omega)$ is the wavenumber, $A(\omega)$ describes the amplitude decay, and the phase velocity, $\mathrm{C}(\omega)$, is determined from the phase term

$$
k(\omega) \Delta r=\frac{\omega}{c(\omega)} \Delta r=\phi(\omega)
$$

A number of seismogram pairs can be used simultaneously to estimate the phase velocity by taking the least-squares solution. The shape of the phase velocity curve can be constrained by limiting the final group velocity to be within some specificd range of the starting model group velocity. The phase term is computed by solving for a correction vector to an initial "assumed" earth model. The data are weighted in the least-squares solution by a weight matrix consisting of a subjective weight factor, which depends on the relative quality of each pair of recordings and on the squared coherence of the data.

The amplitude of high frequency $(>0.04 \mathrm{~Hz})$ surface waves for distant earthquakes is small and correlation of these for propagation paths across the south Caspian basin is difficult. In order to extend the dispersion curves to higher frequencies we use the method of Brune, et al (1960) to determine the phase velocity from events occurring within and on the boundary of the basin. The phase velocity curve may be obtained for a dispersed wave train provided 
the initial phase is known. We have chosen the initial phase so that the phase velocitics at the lowest frequencies in the single station determination will match the phase velocities of the highest frequencies determined by the inter-station method; we then extended the curve to higher frequency, assuming that initial phase is not a function of frequency. Any variation of initial phase as a function of frequency introduces only a small error in phase velocity since the frequency used is high. Poor epicenter location may cause some error in the high frequency part of these data. The uncertainty in the value of phase velocity at any given frequency estimated from this data is probably about $0.03 \mathrm{~km} / \mathrm{sec}$.

Figure 3 compares the fundamental mode Rayleigh wave phase velocity dispersion curve for the south Caspian basin with phase velocity curves measured in two other regions of thick sediments, the Bengal Fan in the northern Indian Ocean (Brune and Singh, 1986) and the Barents Sea (Levshin and Berteussen, 1979; Chan and Mitchell, 1985). The sediments in the northern Bay of Bengal are $\sim 22 \mathrm{~km}$ thick (Brune et al, 1992), similar to the sediment thickness in the south Caspian basin. The Barents Sea is under-lain by $10-25 \mathrm{~km}$ of sediment lying on a $15-32 \mathrm{~km}$ thick crust. This comparison suggests that the thickness of the crystalline crust beneath the sediments in the south Caspian basin is more likely "continental-like" than normal "oceanic-like" crust.

The amplitudes of intermediate frequency surface wave are severely attenuated by propagation across the south Caspian basin. In many cases the recordings on the near side of the basin show well dispersed surface waveforms; however, recordings on the far side of the basin are deficient in intermediate frequency $(0.033-0.10 \mathrm{~Hz})$ surface waves. There are several instances where the stations LNK and KAT lie along the same great circle path for an earthquake and the anomalous effect of propagation across the basin is particularly clear. Examples of this are shown in Figure 4. The top pair of seismograms in this figure show broadband vertical component seismograms, the middle pair show the waveforms high-passed at $22 \mathrm{mHz}$, and the bollom pair show the waveforms low-passed at $22 \mathrm{mHz}$. $\Lambda 11$ wavcforms are plotted on the same time scale and each of the pairs are plotted on the same amplitude scale. In each case the upper seismogram of each pair is the input to the basin and the lower is the output. This shows that there is a well-developed surface wave train for the waveform entering the basin, but the intermediate frequency surface waves are 
greatly reduced in amplitude in the surface wave train emerging from the far side of the basin only $450 \mathrm{~km}$ away. The low frequency surface waves are not significantly affected. Since this effect is observed for both eastward and westward propagating surface waves across the south Caspian basin, the erosion of the intermediate frequency surface waves is not likely to result from a site or instrumental effect.

\section{Surface wave propagation across an idealized south Caspian basin structure}

The anomalous surface wave propagation across the south Caspian basin could possibly result from a number of features of the basin. To isolate the features responsible for the anomalous surface wave propagation, we have computed 2-D finite difference seismograms for an idealized model of the south Caspian basin and the surrounding region. We then perturbed features of the $2-\mathrm{D}$ basin model to see how these affect the surface wave propagation. This procedure shows the effect of 2-D structure on the waveform; however, the crustal structure in the south Caspian region shows large 3-D variations, and 3-D propagation effects, which are not modeled in our finite difference calculations, likely have a significant effect on the observed waveforms.

The idealized south Caspian basin model used in the finite difference computation is shown in Figure 5 and the parameters of the model are tabulated in Table 1. The background velocity model consists of a onc-layer crust over a mantle half-space. The background model is $900 \mathrm{~km}$ wide by $450 \mathrm{~km}$ deep and is gridded at a $1.05-\mathrm{km}$ interval in both distance and depth. The basin lies between $381 \mathrm{~km}$ and $761 \mathrm{~km}$ from the left edge of the grid. The basin crustal model consists of a 2.625 -km thick water layer, a 14.375 -km thick sedimentary layer, and a 16-km thick high velocity lower crustal layer. This simple model emulates the main features of the south Caspian crustal model shown in Figure 1 and is the reference model in the comparisons discussed below. The inputs at the left edge of the finite difference grid are the stresses and displacements as a function of depth for a fundamental mode Rayleigh wave generaled by a $12 \mathrm{~km}$ deep explosion source located $2000 \mathrm{~km}$ away. These were generated by a normal-mode synthetic seismogram code. Although all of the events observed are earthquakes, we have used an explosion source to eliminate potential ambiguities resulting 
from the source radiation pattcrn. Receivers arc placed at $50 \mathrm{~km}$ intcrvals across the model and are located on the solid surface, i.e., in those models with a water layer, the receivers are placed at the water-solid interface. The seismograms are computed with $200000.075 \mathrm{~s}$ time steps.

Figure 6 shows the vertical component synthetic seismograms at a $50 \mathrm{~km}$ interval spacing across the reference model in two pass bands: $<0.020 \mathrm{~Hz}$ (left) and $>0.033 \mathrm{~Hz}$ (right). All seismograms in a record section are plotted at the same amplitude scale, but the two record sections have different scales. The basin effect on the wave train is most pronounced on the high frequency waves, but the basin structure effects are also apparent for the low frequency waves. The high frequency wave train shows an increased amplitude after entering the basin which results from the impedance mismatch across the basin boundary. Small amplitude converted body waves propagate into the basin and small amplitude converted body waves and reflected surface waves propagate back towards the left edge of the model (The amplitudes of these waves are too small to be seen at the amplitude scale used in Figure 6 ). The duration of the surface wave train increases during propagation across the basin due to the increased dispersion resulting from the thick, low velocity sediments; this is shown more clearly in Figure 7 discussed below. High frequency surface waves reverberate in the basin at large travel times. The intermediate frequency surface wave amplitudes on the right side of the figure are reduced after the wave train passes out of the basin and enters the more rigid material on the right side of the basin. The highest frequency components in the low frequency pass band are also amplified upon entering the basin as well as reflected back towards the left edge of the model. Surface waves of these frequencies are affected by the increased dispersion across the basin and are attenuated on passing out of the basin. The lowest frequency component shows little effect of the basin structure.

To isolate the features which most contributed to the anomalous surface wave propagation, we next perturbed the basin model velocity and attenuation structure in a number of ways and compared synthetic seismograms computed for these models with those computcd for the reference model. Most of the structural features of the basin such as the thickness of the crystalline crust beneath the basin, degree of mantle up-warp beneath the basin, shape of the basin boundaries, etc, had little effect on the synthetic seismograms compared to 
the seismograms of the reference model. The features which significantly influence the surface waveforms are the sediment thickness and the attenuation structure of the basin, and these are shown in Figure 7. This figure compares high- and low-passed finite difference seismograms at distance 350 and $800 \mathrm{~km}$ from the left-hand edge of the model. All of the seismograms in each passband are plotted at the same amplitude scale but the amplitude scale for the two pass-bands is different. The light trace is the synthetic seismogram computed for the reference model (Fig. 5); the dark trace is the synthetic seismogram computed after altering one of the parameters. Figure 8 makes the same comparison but in the frequency domain. The pair of traces at middle left labeled BASIN INPUT are the high-pass and low pass seismograms at $350 \mathrm{~km}$ near to the left edge of the basin. The pairs of scismograms above, to the right, and below the input seismograms are the the seismograms at $850 \mathrm{~km}$ after emerging from the basin.

The seismogram pair labeled NO BASIN demonstrate the increased dispersion of the basin structure, primarily the thick, low velocity sediments. The high-passed seismogram is extended in time, but only the highest frequency components of the low-passed seismogram are affected by the basin structure. Increasing the sediment thickness from 14.4 to 22.4 $\mathrm{km}$ has a small additional dispersion effect on the high-passed seismogram, but the thicker sediments have a increased effect on the low-pass seismogram. Decreasing the $Q_{\beta}$ in the sediments from 50 to 10 reduces the amplitude of the high-pass waveform by more than a factor of 2 but has only a small effect on the low-pass waveform. Increasing the attenuation in the mantle beneath the basin does not significantly lower the low-pass waveform amplitudes.

The two pairs of seismogram labeled SLOPING SIDES and EXTENDED BASIN show effects of the configuration of the basin boundaries. The basin model with sloping boundaries has a basin transition from the surrounding model which extends over a $45 \mathrm{~km}$ distance rather than the abrupt boundaries of the reference model. This gradational basin boundary has little effect on the synthetic seismogram. The basin model labeled EXTENDED BASIN has a two-step basin boundary with the sediments extending to a depth of $10 \mathrm{~km}$ beneath the stations and the same depth as the reference model in the interior of the basin. In this model the observation points are effectively within the basin and are more in agreement with the receiver function analysis (Mangino and Priestley, 1998). These seismograms show an 
enhancement of the high-pass waveform but there is little effect on the low-pass wavcform. This shows up in the spectral ratio as a spectral resonance peak at about $0.04 \mathrm{HZ}$. Halving the sediment thickness increases the frequency of this peak slightly, but it primarily reduces the amplitude of the spectral peak.

Figure 9 compares the observed fundamental mode Rayleigh wave spectral ratio between stations LNK and KAT and the phase velocity dispersion for the south Caspian basin (Fig. 3) with the spectral ratios and phase velocity dispersion for the various finite difference models. The dispersion curves are included only for reference since the finite difference models are oversimplified in terms of the velocity structure. The KAT-LNK spectral ratio is near one at $0.01 \mathrm{~Hz}$. Between about 0.017 and $0.033 \mathrm{~Hz}$ the spectral amplitude decays by more than a factor of three. At frequencies higher than $0.033 \mathrm{~Hz}$ the spectral ratio increases with a peak near $0.05 \mathrm{~Hz}$. The upper panel of Figure 9 shows that increasing the sediment thickness to $22.4 \mathrm{~km}$ or decreasing the sediment Q to 10 attenuates the high frequency surface waves but does not produce the attenuation in the 0.02 to $0.03 \mathrm{~Hz}$ band seen in the data. Increasing the attenuation in the mantle beneath the basin (Fig. 9 - lower panel) reduces the low frequency amplitudes but not to the extent observed in the data. The data show a large amplitude peak between 0.04 and $0.05 \mathrm{~Hz}$. Extending the basin sediments beneath the observation points in the finite difference model causes a lower amplitude, lower frequency resonance peak. No variations of the south Caspian basin model (Fig. 5) reduced the energy in the 0.02 to 0.03 $\mathrm{Hz}$ band in the synthetic seismograms to the degree seen in the KAT-LNK seismograms.

\section{Discussion and Conclusions}

The south Caspian is an actively subsiding basin with extremely high rates of Cenozoic sedimentation, in some places as high as $1,300 \mathrm{~m} / \mathrm{my}$. Figure 1 shows that the basin contains an enormous thickness of sediments, as much as $25 \mathrm{~km}$ in the deepest parts. Borehole data in the Caspian Sea south of Baku show that to at least $5 \mathrm{~km}$ depth these sediments consist of both sand and shale beds that have pore-fluid pressure substantially in excess of hydrostatic

fluid pressure (Bredehoeft et al, 1988). This high pore--fluid pressure is the likely cause of the large number of mud volcanos found along the coast and on the bed of the south Caspian 
Sea.

The thick sediments have a pronounced effect on the propagation of surface waves. Intermediate frequency $(>22 \mathrm{mHz})$ surface waves are severely affected in propagating across the south Caspian basin whereas low frequency $(<22 \mathrm{mHz})$ surface waves show little effect of the basin structure. We have used a hybrid normal mode-finite difference program and a simplified model of the south Caspian basin to study which of the basin features cause the anomalous effect on the surface wave propagation. Variations in the velocity of the crystalline crust of the basin and in the mantle up-warp beneath the basin result in a small part of the surface wave energy being converted into body waves and being lost, but on the whole these features have little effect on the intermediate frequency surface waves. The thick, highly attenuating sediments do have a significant effect on the surface waveform. This results from (1) the increased high frequency dispersion which gives an apparent decrease in amplitude by stretching the waveform out in time and (2) the high attenuation of the sediments which has a large effect on the high frequency surface waves but little effect on the low frequency surface waves.

The 2-D finite difference modeling has reproduced a number of trends in the data but not the details. There are strong 3-D variations in the crustal structure in the region of the south Caspian basin. The Talesh mountains form the western boundary, the Alborz mountains constitute the southern boundary, and the Kopet Dag and Alborz mountains form the eastern boundary. The Apshceron-Balkhan sill, a seismically active shallow ridge separating the northern and south Caspian, makes up the northern boundary of the basin. The station LNK lies between the Talesh Mountains and the southwest Caspian coast and on about $10 \mathrm{~km}$ of sediment. Station KAT is in the west Turkmenian lowlands east of the south Caspian basin located in a large sedimentary basin considered to be structurally part of the south Caspian basin. The effects of the complex structure are apparent in the data. Surface wave polarization measurements of the back-azimuth vs. frequency show that the low frequency $(<0.033 \mathrm{~Hz})$ Rayleigh waves arrive near the theoretical source-receiver great circle azimuth, whereas there is considerable scatter in the azimuth of approach of the higher frequency surface waves. This result suggest that 3-D effects could be important for amplitudes at high frequency. 


\section{Acknowledgments}

This research was supported by the Department of Energy through Contract F1962895-K-0017 (KP) administered by the U.S. Air Force Phillips Laboratory, Hanscom AFB, Massachusetts and under the auspices of the U.S. Department of Energy by LANL under contract W-7405-ENG-36 (HP) and LLNL under contract W-7405-ENG-48 (CS). 


\section{References}

Bredehoeft, J.D, R.D. Djevanshir, and K.R. Belitz (1988). Lateral fluid flow in a compacting sand-shale sequence: south Caspian basin, Am. Assoc. Petroleum Geologists Bull., 72 , 416-424.

Brune, J., J. Nafe, and J. Oliver (1960). A simplified method for the analysis and synthesis of dispersed wave trains, J. geophys. Res., 65, 287-304.

Brune, J., and D.D. Singh (1986). Continent-like crustal thickness beneath the Bay of Bengal sediments, Bull. seism. Soc. Am., 76, 191-203.

Brune, J., J. Curry, L. Dorman, and R. Raitt (1992). A proposed super-thick sedimentary basin, Geophys. Res. Letts., 19, 565-568.

Chan, W.W., and B.J. Mitchell (1985). Surface wave dispersion, crustal structure, and sediment thickness variations across the Barents shelf, Geophys. J. R. astr. Soc., 80, 329-344.

Gal'perin, Y., I. Kosminskaya, and P. Krakshina (1962). Main characteristics of deep waves recorded during deep seismic sounding in cenlral parl of Caspian sea. In: Deep Seismic Sounding of the Earth's crust in the U.S.S.R., Acad. Sci. USSR, Moscow.

Gomberg, J.S., K.F. Priestley, T.G. Masters, and J.N. Brune (1988). The structure of the crust and upper mantle of northern Mexico, Geophys. J., 94, 1-20.

Isacks, B., and C. Stephens (1975). Conversion of $\mathrm{S}_{\mathrm{n}}$ to $\mathrm{L}_{\mathrm{g}}$ at a continental margin, Bull. seism. Soc. Am., 65, 235-244.

Kadinsky-Cade, K., M. Barazangi, J. Oliver, and B. Isacks (1981). Lateral variations of high frequency seismic wave propagation at regional distances across the Turkish and Iranian Plateaus, J. geophys. Res., 86, 9377-9396.

Levshin, A. and K.-A. Berteussen (1979). Anomalous propagation of surface waves in the Barents Sea as inferred from NORSAR recordings, Geophys. J. R. astr. Soc., 56, 97-118. Mangino, S. and K. Priestley (1998). The crustal structure of the southern Caspian region, Geophys. J. Int., in press.

Mindeli, P.S., Yu.P. Neprochnov, and E.I. Pataraya (1965). Definition of the area without granitic layer in the Black Sea basin on DSS data and seismology, Izv. Earth Phys., 12, 
$7-15$.

Neprochnov, Yu.P., (1968). Structure of the Earth's crust of epi-continental seas: Caspian, Black and Mediterranean, Can. J. Earth Sci., 5, 1037-1043.

Neprochnov, Yu.P., I.P. Kosminskaya, and YA.P. Malovitsky (1970). Structure of the crust and upper mantle of the Black and Caspian Seas, Tectonophys., 10, 517-538.

Press, F., and M. Ewing (1952). Two slow surface waves across North America, Bull. seism. Soc. Am., 42, 219-228.

Rezanov, I.A., and S.S. Chamo (1969). Reasons for absence of a granitic layer in basins of the South Caspian and Black Sea type, Can. J. Earth Sci., 6, 671-678.

Savarensky, E.F., and N.G. Valdncr (1960). $\mathrm{L}_{\mathrm{g}}$ and $R_{g}$ waves from earthquakes of the area of the Black Sea and some consideration about their origin, Seismic Investigation Geofiz. Com. U.S.S.R., Akademizdat, 4, 55-77.

Seber, D, M. Barazangi, B.A. Tadili, M. Ramdani, A. Ibenbrahim, D.B. Sari, and S.O.E. Alami (1993). $S_{n}$ to $S_{g}$ conversion and focusing along the Atlantic margin, Morocco: Implications for earthquake hazards evaluation, Geophys. Res. Letts., 20, 1503-1506.

Shapiro, N., N. Bethoux, M. Campillo, and A. Paul (1996). Regional seismic phases across the Ligurian Sea: $\mathrm{L}_{\mathrm{g}}$ blockage and oceanic propagation, Phys. Earth planet. Int., 93, $257-268$.

Shurbet, D.H., (1964). The high-frequency S phase and the structure of the upper mantle, J. geophys. Res., 69, 2065-2070.

Shurbet, D.H., (1975). Conversion of $\mathrm{S}_{\mathrm{n}}$ at a continental margin, Bull. seism. Soc. Am., 65, $327-329$.

Yegorkin, A.V. and B.A. Matushkin (1970). Crustal structure of the Caucasus and Western Central Asia based on geophysical sounding data, Internat. Geol. Rev., 12, 281-290. 
Department of Earth Sciences

Bullard Laboratories

Cambridge University

Cambridge CB3 0EZ, United Kingdom

(K.P.)

Geophysics Group, EES3

Los Alamos Nalional Laboratory

Los Alamos, New Mexico 87545

(H.P.)

Environmental Programs Directorate

Lawrence Livermore National Laboratory

Livermore, California 94551

(C.S.) 
Table 1

\begin{tabular}{ccccccc} 
Model & $\begin{array}{c}\text { Thickness } \\
(\mathrm{km})\end{array}$ & $\begin{array}{c}\mathbf{V}_{\mathbf{p}} \\
\mathbf{k m ~ s}\end{array}$ & $\begin{array}{c}\mathbf{V}_{\mathbf{s}} \\
\mathbf{k m ~ s}^{-\mathbf{1}}\end{array}$ & $\begin{array}{c}\rho \\
\mathbf{g m ~ c m}^{-\mathbf{3}}\end{array}$ & $\mathbf{Q}_{\mathbf{p}}$ & $\mathbf{Q}_{\mathbf{s}}$ \\
\hline Background Model & 38.0 & 6.40 & 3.70 & 2.82 & $\infty$ & $\infty$ \\
& 450.5 & 8.13 & 4.70 & 3.37 & $\infty$ & $\infty$ \\
\hline Basin Model & 2.625 & 1.51 & 0.00 & 1.00 & $\infty$ & $\infty$ \\
& 14.375 & 3.46 & 2.00 & 1.88 & 100 & 50 \\
& 16.000 & 7.44 & 4.30 & 3.15 & 1000 & 500 \\
\hline
\end{tabular}




\section{Figurc Captions}

Figure 1. The upper part of this figure shows a location map of the south Caspian region. The solid inverted triangles denote CSN stations used in the receiver function study of Mangino and Priestley (1998); the solid black lines denote the location of DSS profiles used by Mangino and Priestley (1998) to construct the crustal velocity model for the south Caspian region shown in the lower part of the figure. The crustal cross-section corresponds approximately to the region of the box on the map. The three crustal and single mantle layers are characterized by their $\mathrm{P}$-wave velocities: sediment and consolidated sediment $\left(\mathrm{V}_{\mathrm{p}}<4.8 \mathrm{~km} \mathrm{~s}^{-1}\right.$ ), "granitic" ( $\mathrm{V}_{\mathrm{p}}$ between $4.8-6.4 \mathrm{~km} \mathrm{~s}^{-1}$ ), and "basaltic" ( $V_{\mathrm{p}}$ between $\left.6.4-7.4 \mathrm{~km} \mathrm{~s}^{-1}\right)$; upper mantle are $\mathrm{V}_{\mathrm{p}} \geq 8.0 \mathrm{~km} \mathrm{~s}^{-1}$. In this study we have measured fundamental mode Rayleigh wave phase velocities between the station pairs KAT-KRF, KRF-LNK, and LNK-KAT.

Figure 2. Regional seismograms of an earthquake occurring near KRF (Fig. 1) and recorded at stations LNK, KAT, and ABKT. The inset map shows the propagation paths to each of the CSN seismographs. Double arrows indicate the times of the $\mathrm{L}_{\mathrm{g}}$ window corresponding to group velocities of 3.6 and $3.2 \mathrm{~km} / \mathrm{s}$.

Figure 3. Comparison of the fundamental mode Rayleigh wave phase velocity curve measured for the south Caspian basin with curves measured in two other regions of anomalously thick sediments.

Figure 4. Example of the anomalous effect of the south Caspian basin structure on the propagation of intermediate frequency surface waves. The Jan. 25, 1994 earthquake is propagating from west-to- east on the same great circle path as that between LNK and KAT: the LNK seismogram is the basin input and the KAT seismogram is the basin output. The upper pair of seismograms are the broadband records, the middle pair are the high-passed records, and the bottom pair are the low-passed records. Each pair of seismograms is plotted with the same amplitude scale, but the amplitude scales differ for each pair. The July 13, 1994 earthquake is propagating from east-to-west along the same great circle path as that between KAT and LNK: the KAT seismogram is the basin input and the LNK seismogram is the basin output. 
Figurc 5. Simplified model of the south Caspian basin used in the finite differencc calculations. The parameters of the model used in the finite difference calculation are given in Table 1. This model is called the reference model in the text.

Figure 6. Low-pass and high-pass record sections of the finite difference seismograms computed for the reference model shown in Figure 5. Arrows indicate the basin boundaries. The seismograms are plotted at a $50 \mathrm{~km}$ interval across the model.

Figure 7. Comparison of basin input and output finite difference synthetic seismograms for six perturbations of the reference model (Figure 5) structure. In each comparison the light background seismogram is the synthetic computed for the reference model and the darker seismogram is computed for the perturbed model. The upper seismogram of each pair is the high-pass ( $>0.033 \mathrm{~Hz}$ ) filtered record and the lower seismogram is the low-pass $(<0.02 \mathrm{~Hz})$ filtered record. The input seismogram is at $350 \mathrm{~km}$ distance across the model and the output seismogram is at $800 \mathrm{~km}$ distance across the model.

Figure 8. Comparison of the spectral ratios computed for the seismograms in Figure 7 with the spectral ratio for the reference model (unlabeled dark line).

Figure 9. Comparison of the same spectral ratios (left panels) shown in Figure 8 with the average spectral ratio measured between LNK and KAT (dark line). On the right are shown the fundamental mode phase velocity for the various finite difference models compared to the observed phase velocity. 

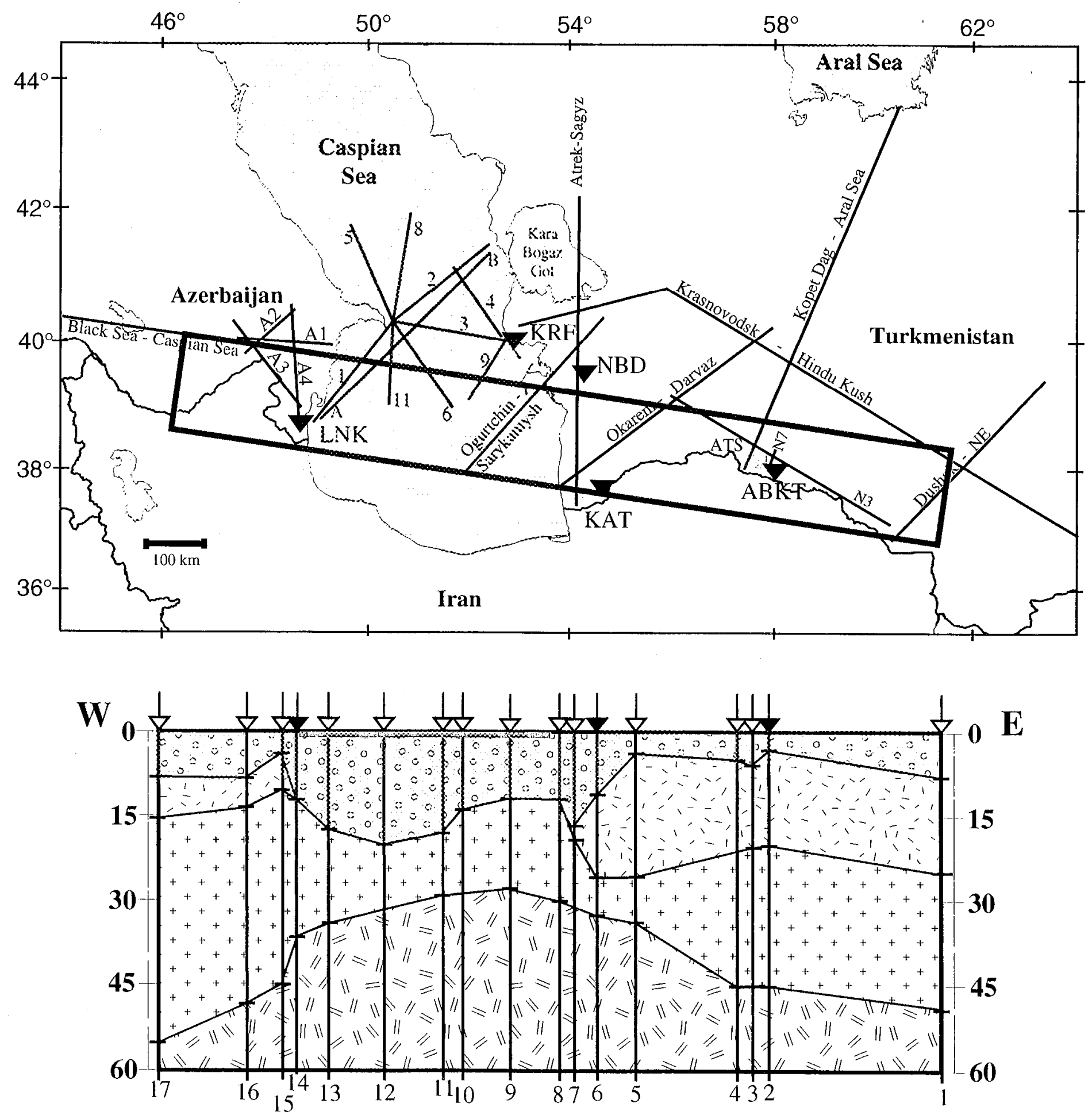

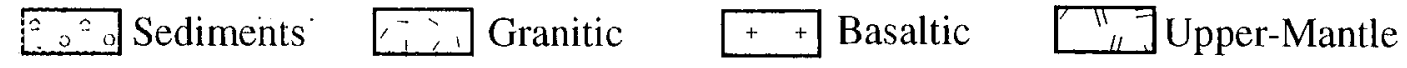

Figure 1 

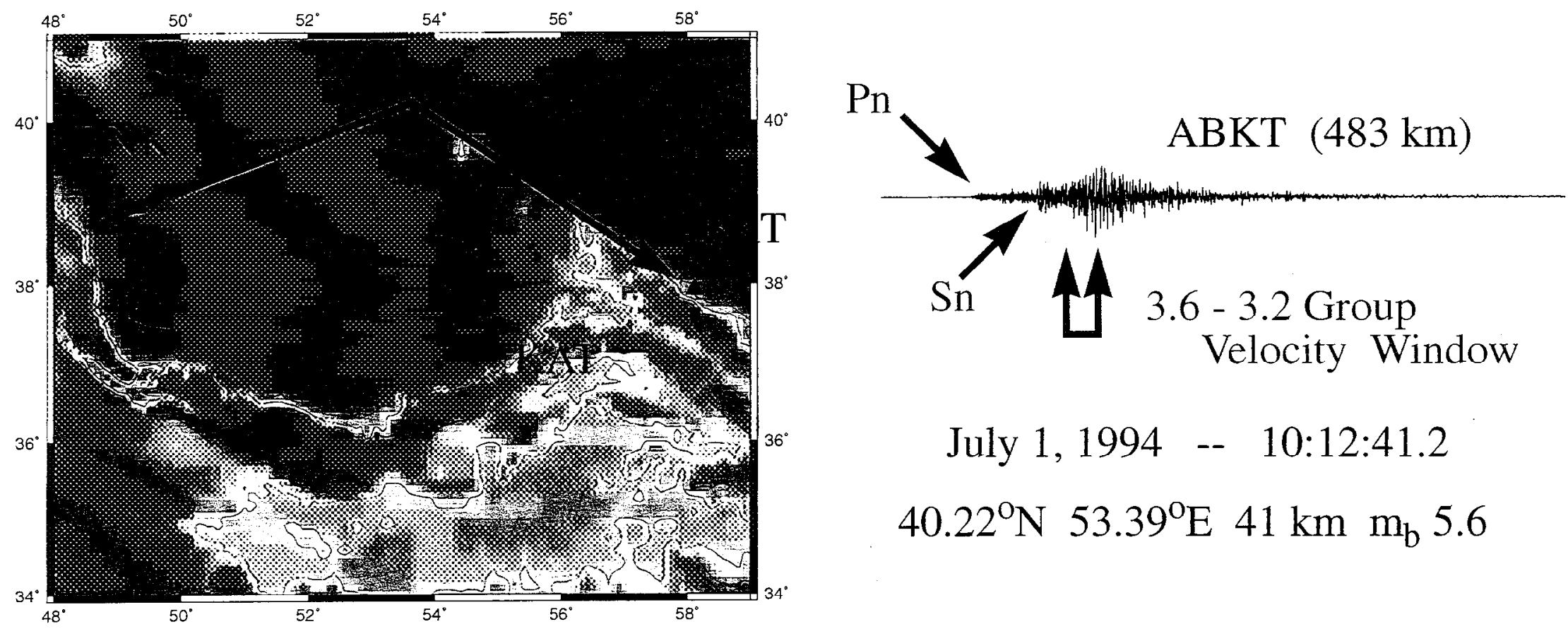

$$
\begin{gathered}
\text { July } 1,1994 \quad--\quad 10: 12: 41.2 \\
40.22^{\circ} \mathrm{N} 53.39^{\circ} \mathrm{E} \quad 41 \mathrm{~km} \mathrm{~m}_{\mathrm{b}} 5.6
\end{gathered}
$$
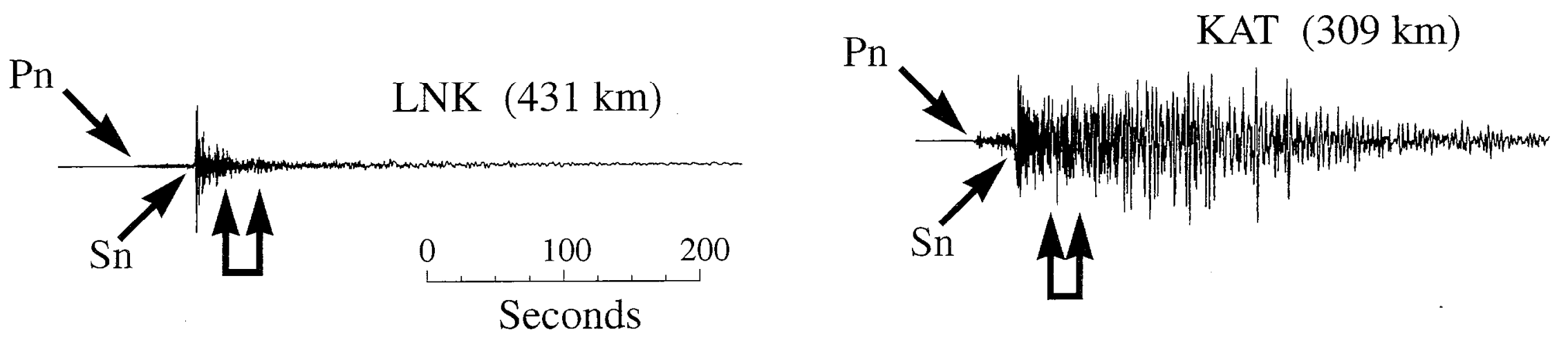

Figure 2 
Fundamental Mode Rayleigh Wave Dispersion

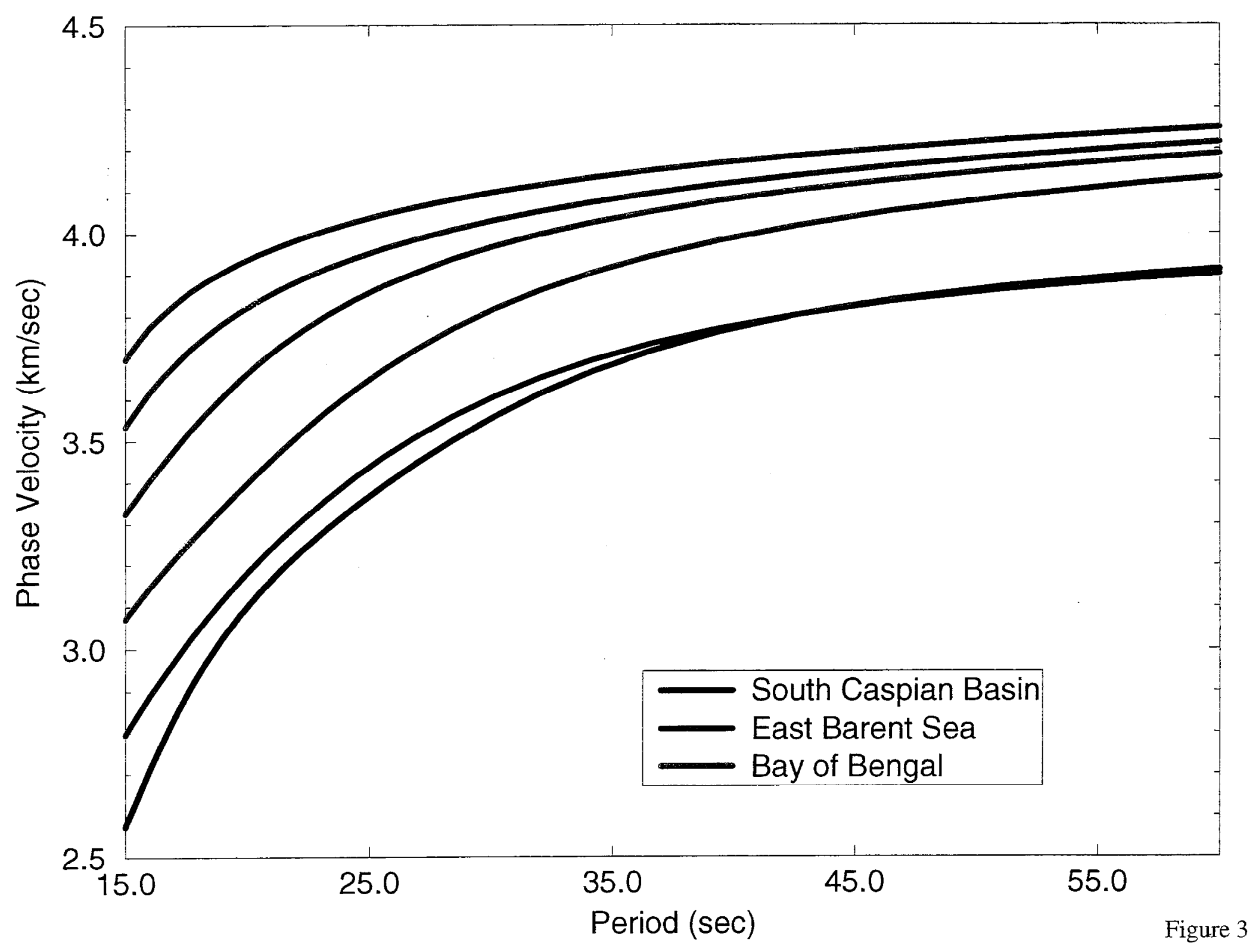


Jan. 25, 1994 -- 7:12:44.8 -- Mid-Atlantic Ridge

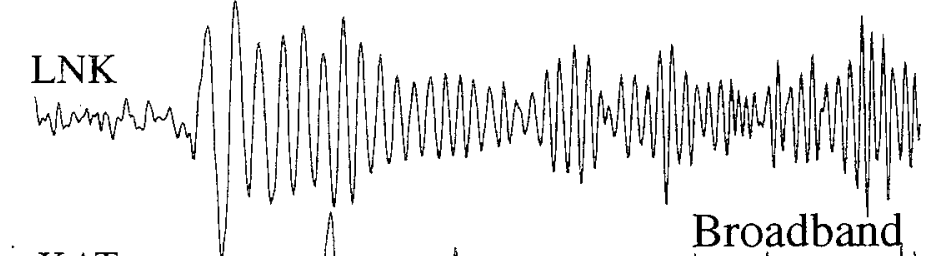
KAT LNK KAT $>22 \mathrm{mHz}$ KAT

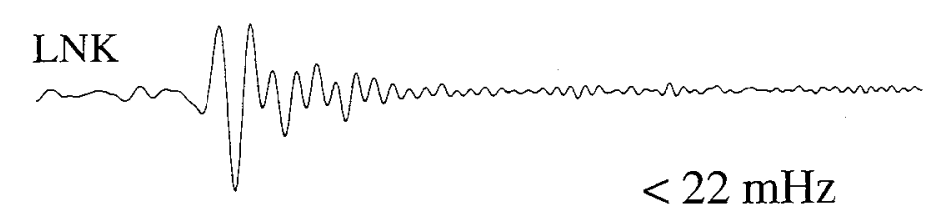

KAT

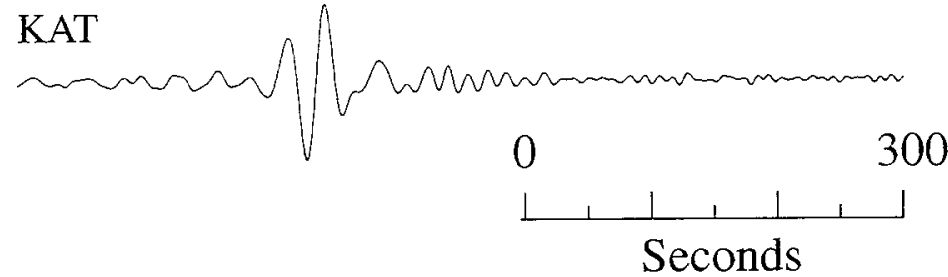

July 13, 1994 -- 11:45:23.3 -- Timor

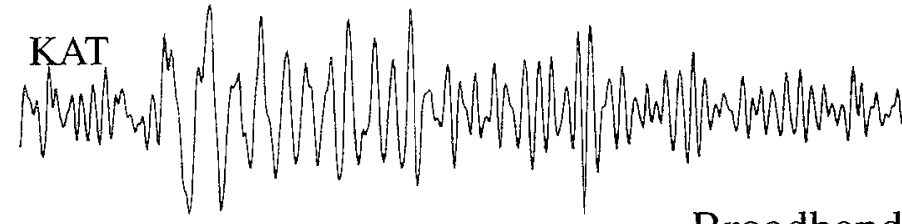

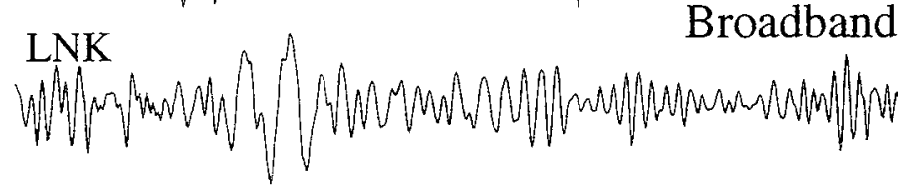

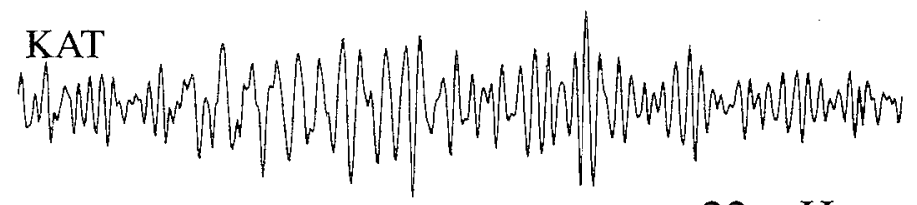
LNK $>22 \mathrm{mHz}$

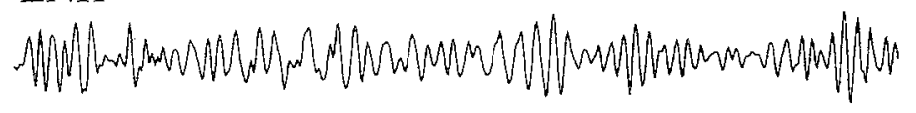

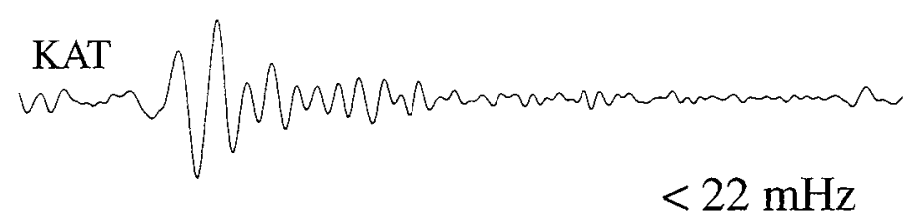

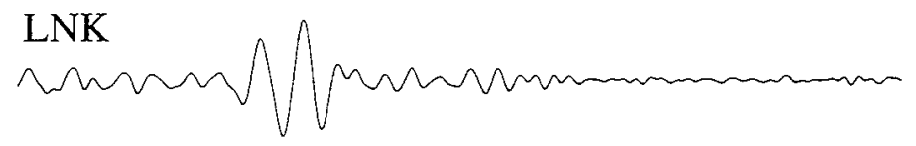




\section{Simplified South Caspian Basin Model}

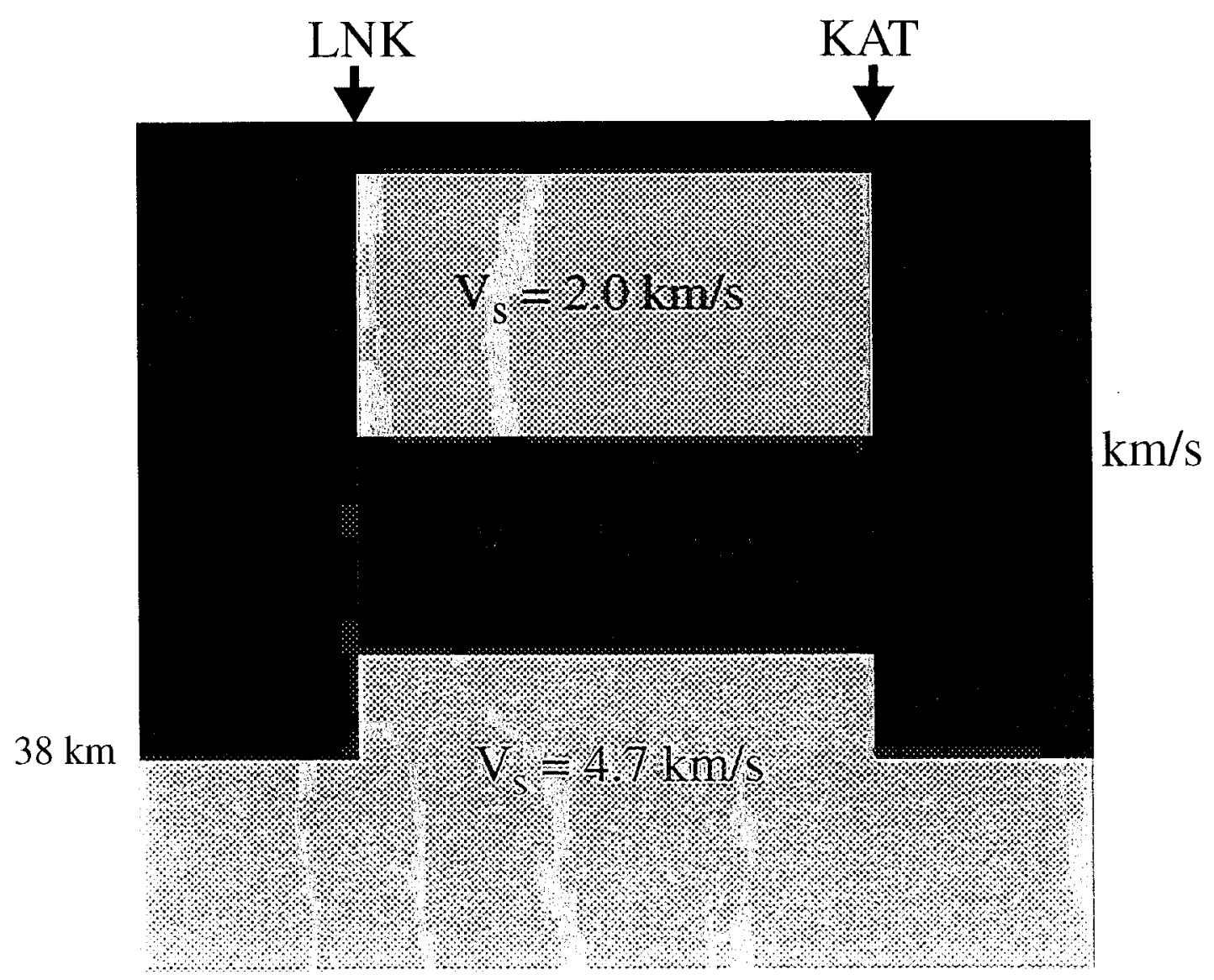

Figure 5 

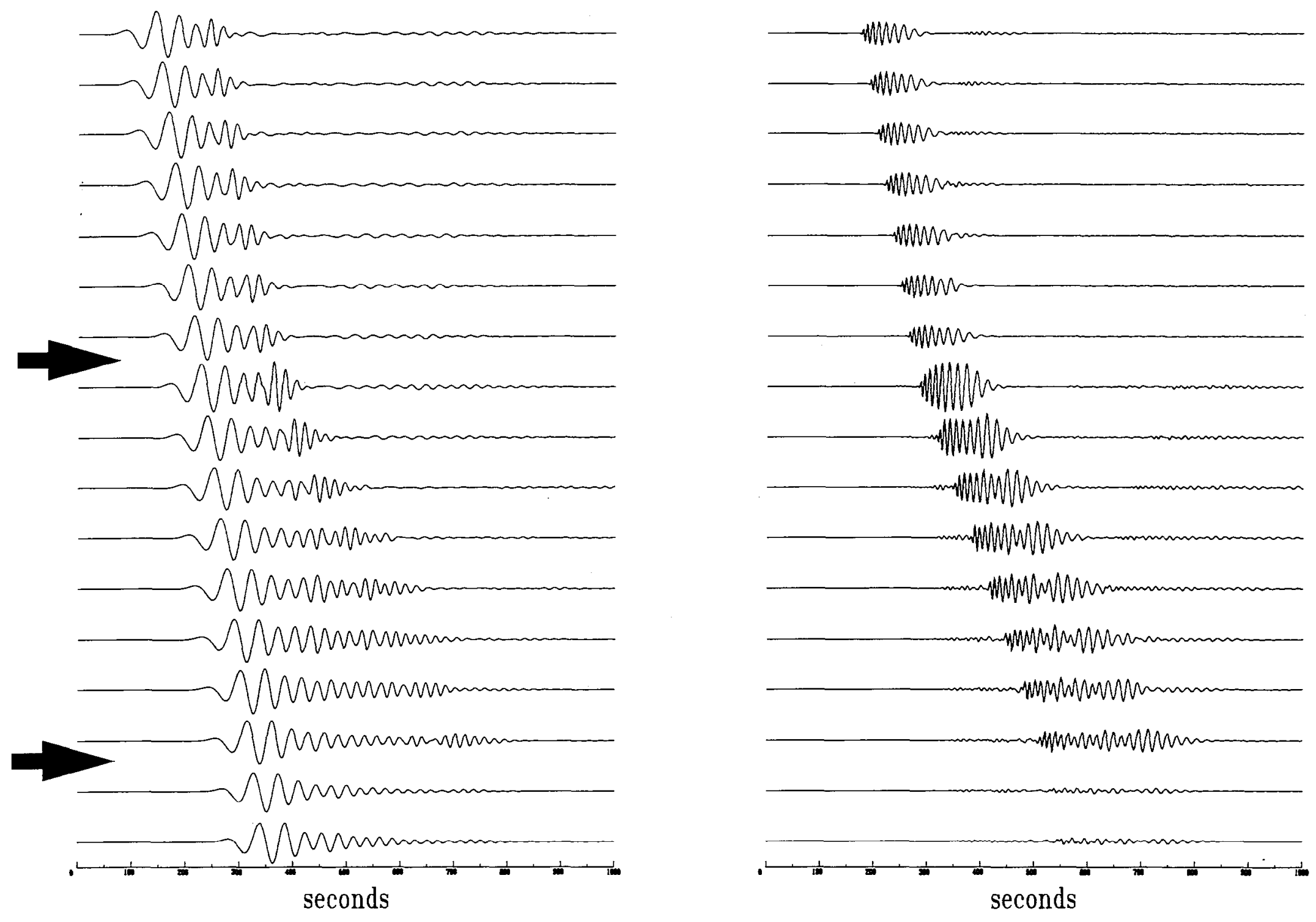

Figure 6 


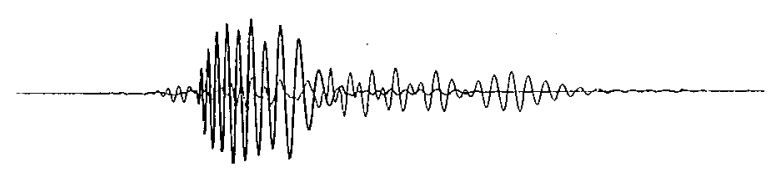

NO BASIN
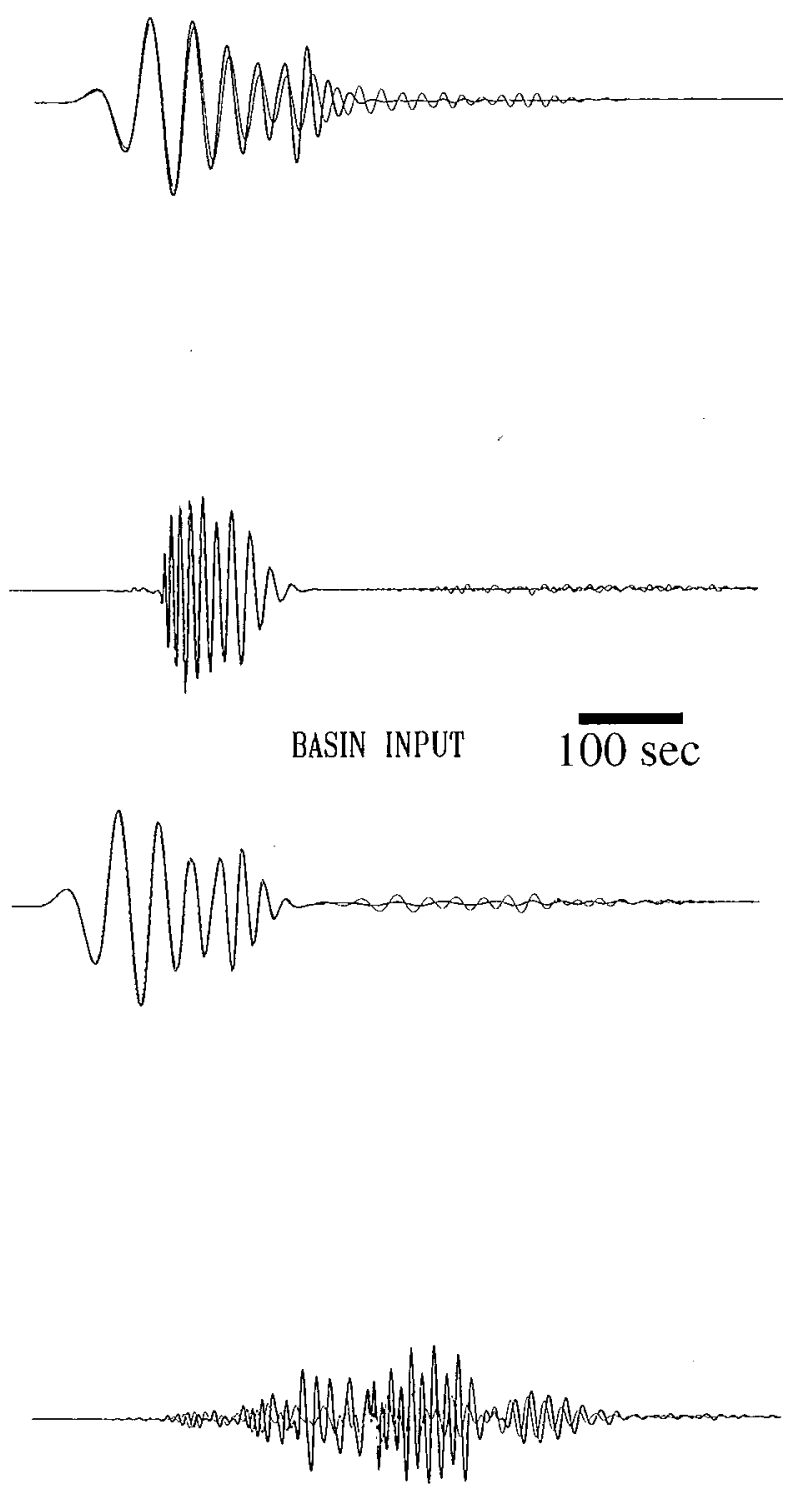

EXTENDED BASIN

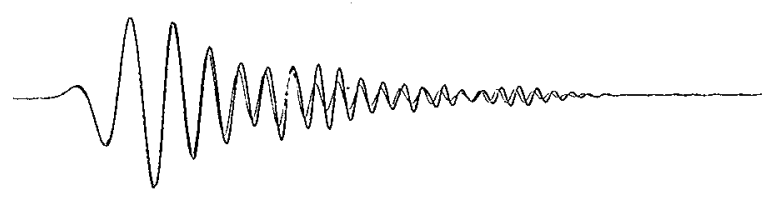

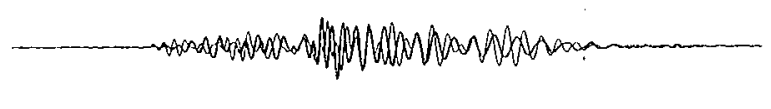

INCREASED SEDIMENT THICKNESS
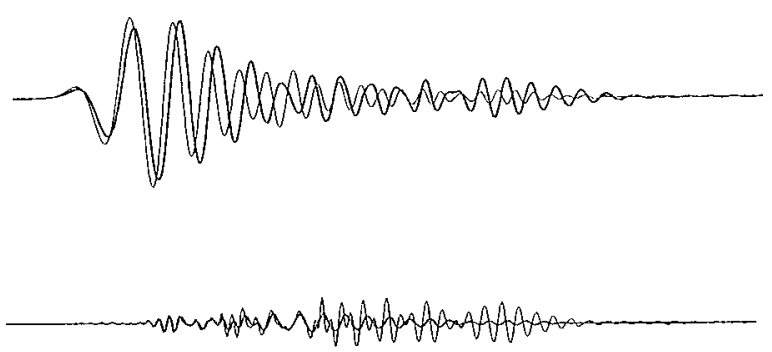

INCREASED SEDIMENT ATTENUATION
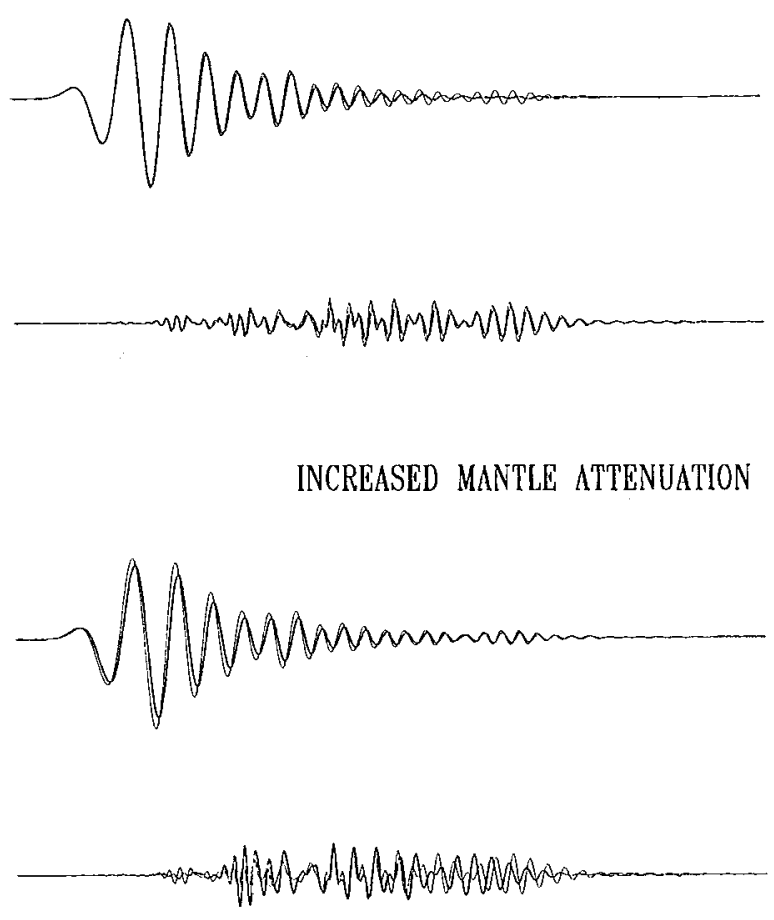

SLOPING SIDES

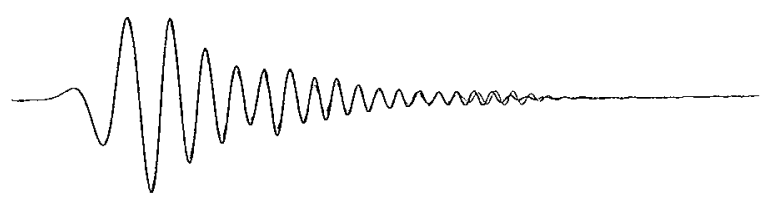

Figure 7 


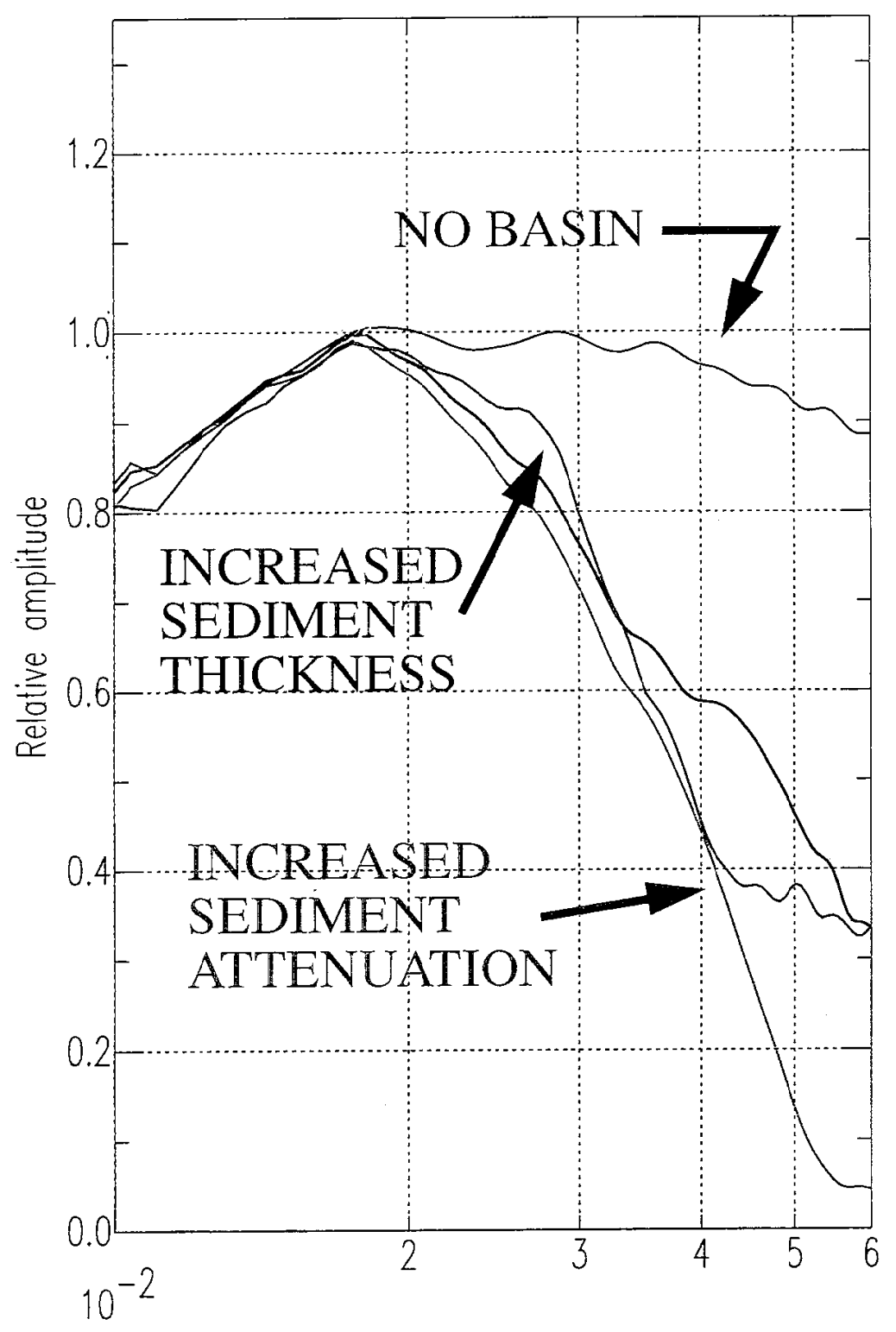

Frequency $(\mathrm{Hz})$

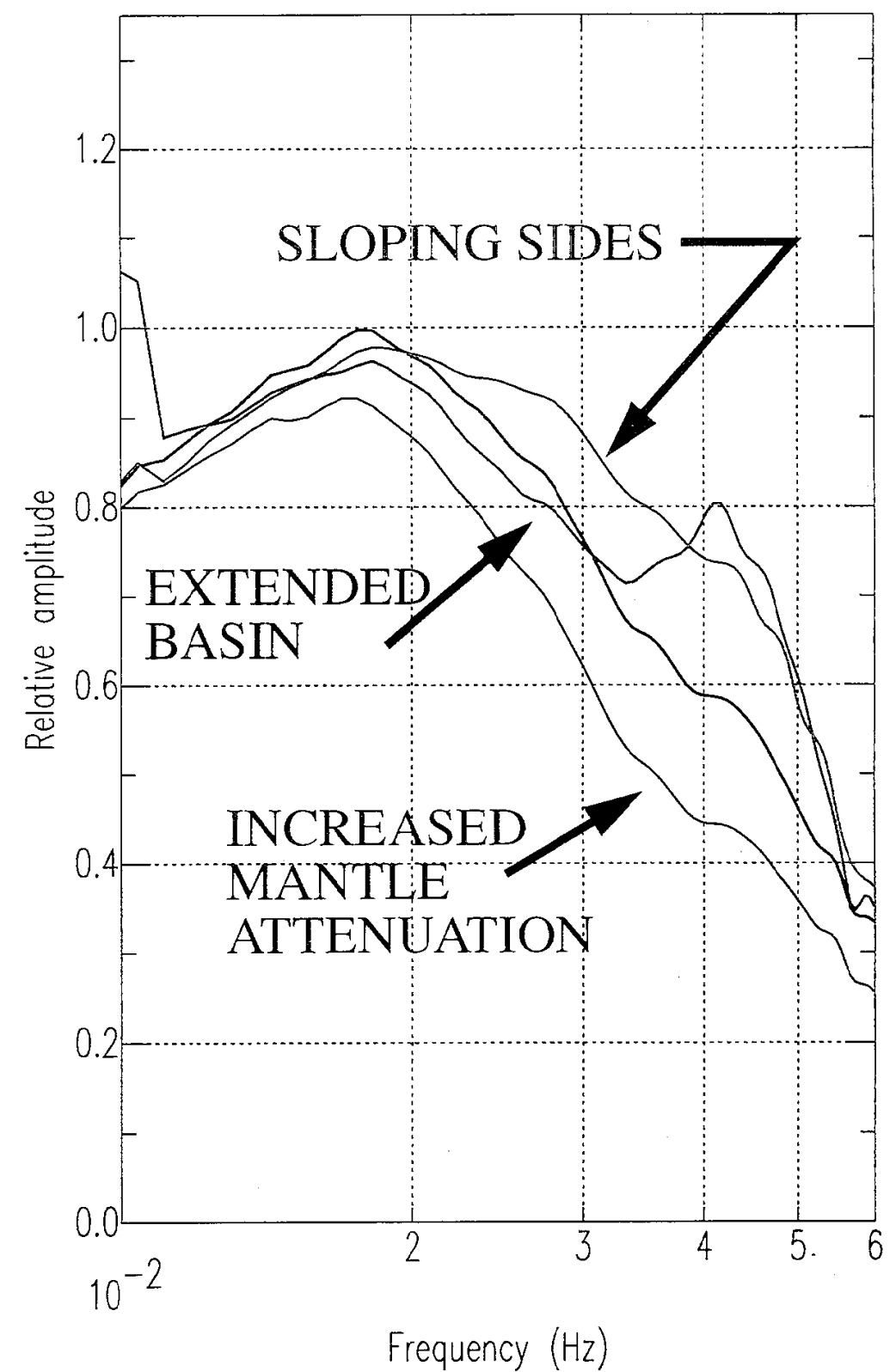

Figure 8 

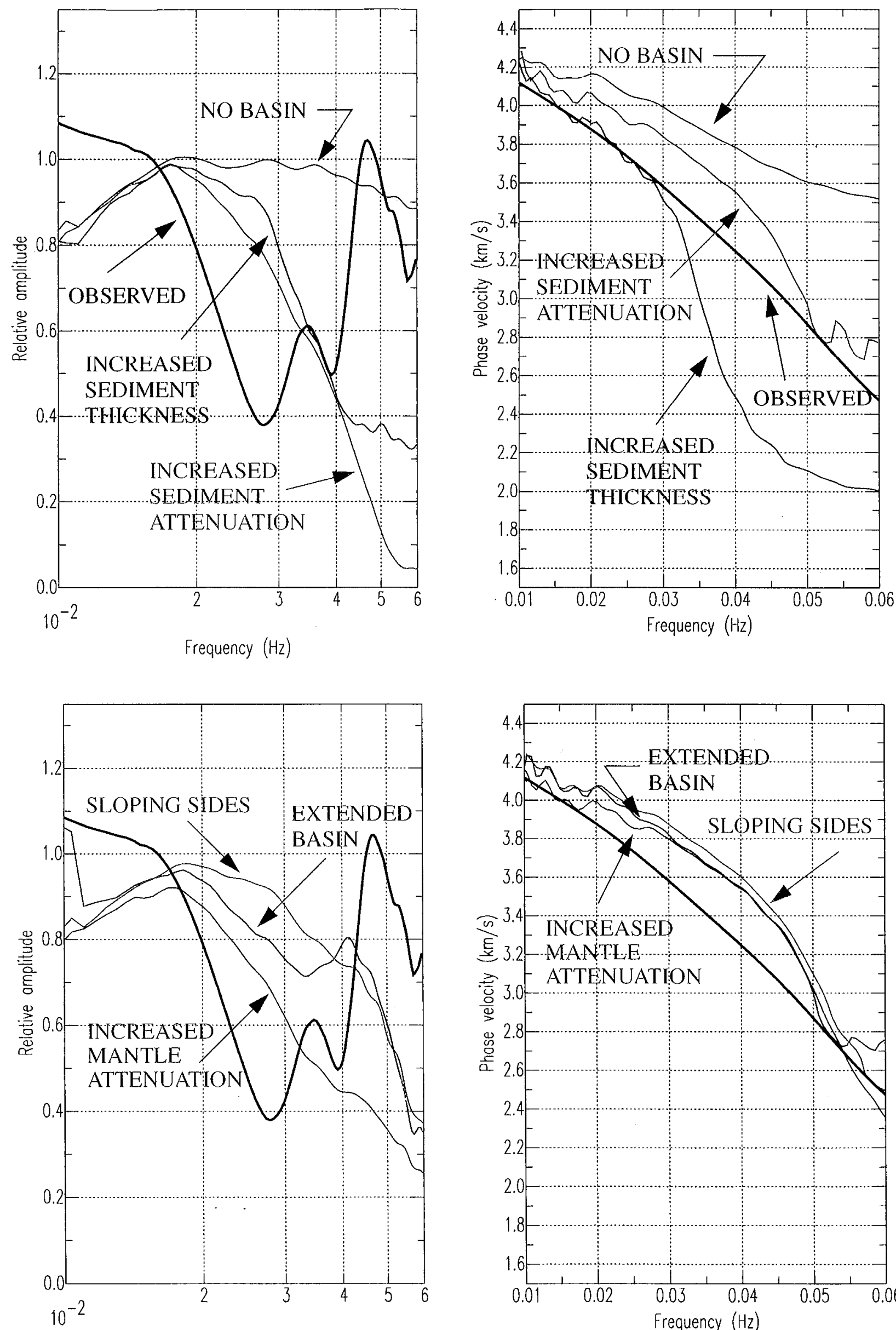

Frequency $(\mathrm{Hz})$

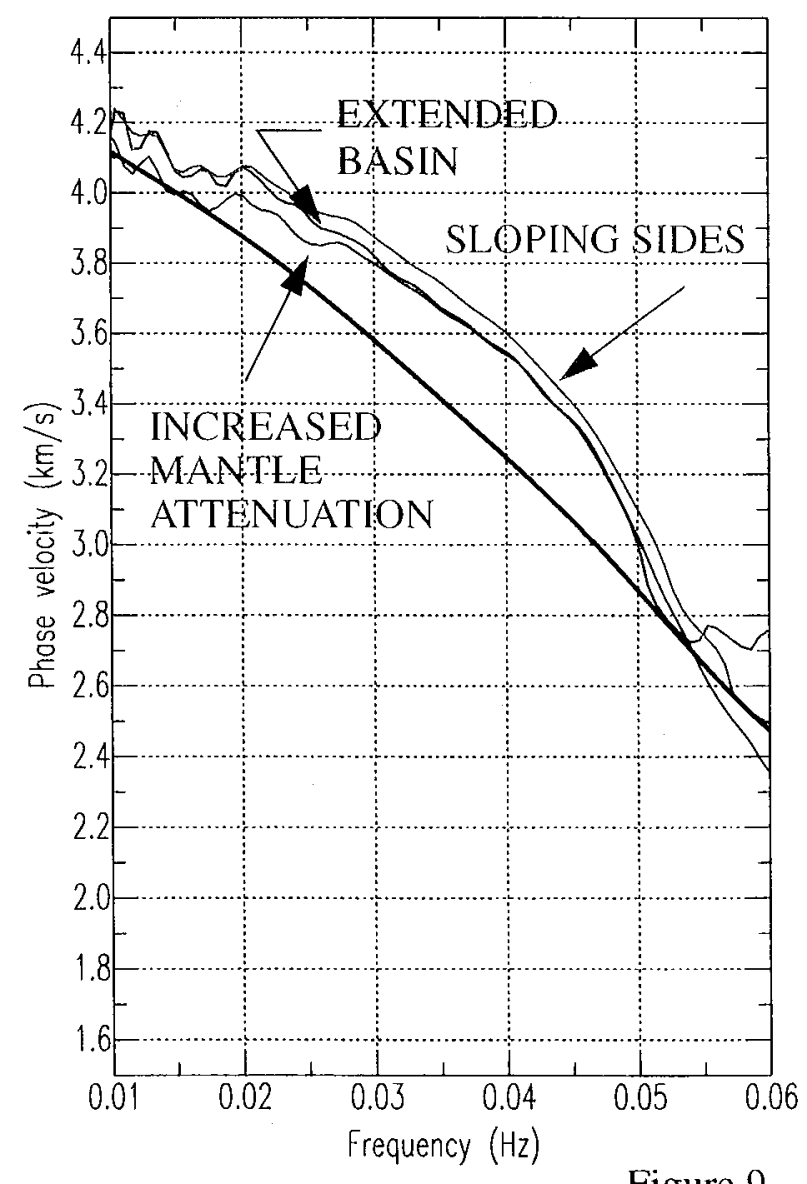

Figure 9 


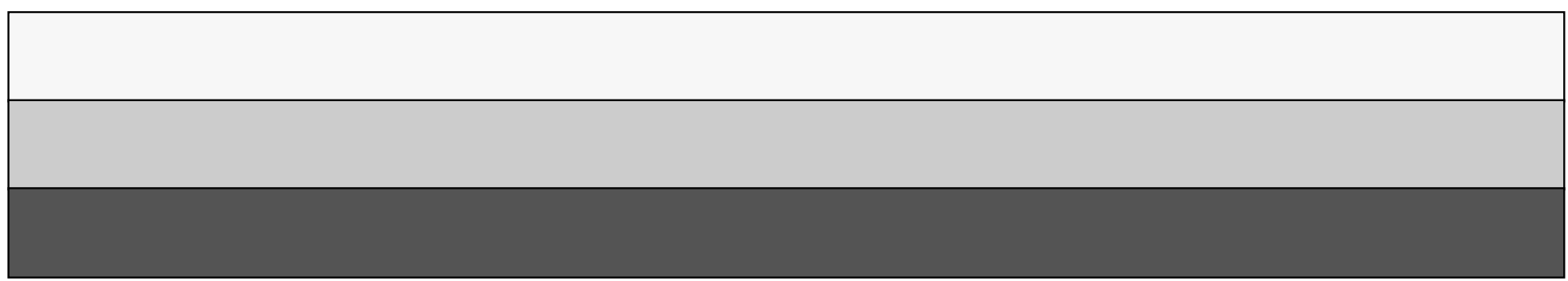

